\title{
Design synthesis and structural optimization of a lightweight, monobloc cast iron brake disc with fingered hub
}

\author{
Stergios Topouris and Marko Tirovic* \\ Cranfield University, School of Aerospace, Transport and Manufacturing, \\ College Road, Cranfield, MK43 OAL, United Kingdom \\ * Corresponding author: m.tirovic@cranfield.ac.uk
}




\section{Design synthesis and structural optimization of a lightweight, monobloc cast iron brake disc with fingered hub}

The article focuses on generating a monoblock fingered hub (top hat) disc design, aiming at reducing disc mass but maintaining rotor thermal capacity, whilst also improving heat dissipation characteristics. The analyses and tests demonstrated that such a design is possible to achieve, with mass reduction of just over $9 \%$. The activities included research into cast iron modelling which gave very important insight into its limits of mechanical performance under bending. Initial Finite Element analyses enabled considerable progress towards establishing a baseline design but only through Shape Optimization and Topology Optimization procedures the full potential of the design have been accomplished. Shape optimization facilitated reduction of maximum principal stress by $32 \%$, considerably improving disc torsional strength with practically no mass increase. The safety factor in torsion achieved the value of 3.57. Topology Optimization provided further, though small mass reduction (1.5\%) whilst maintaining low stress levels.

Keywords: Brake Disc, Cast Iron Properties, Finite Element Analysis, Shape Optimization, Topology Optimization

\section{Introduction}

\subsection{Background, Aims and Objectives}

The development of this disc design was motivated by the need to reduce vehicle unsprung mass and improve brake cooling characteristics. Fingered type discs have typically several parts (i.e. rotor, hub and a number of connecting components), requiring accurate machining and assembling which considerably increase the cost. Such designs are necessary in large railway brake discs, where the discs are of a much more substantial 
thickness and mass, and where the thermal expansion at disc inner diameter is large (typically over $1 \mathrm{~mm}$ radially). Such discs are much more expensive and additional machining and assembly costs represent relatively small fraction of the total brake assembly costs. However, in passenger cars, cost increase can only be justified for a high performance brakes and vehicles or when the disc is offered as an aftermarket product. However, the benefits in the reduction of disc stresses and coning typically does not come only with higher costs, as there are other potentially negative effects. Due to the limited space, the gaps between the rotor and hub are often relatively small, compromising air entry necessary for effective convective cooling inside the channels. The approach presented here is aiming at creating a single piece (monobloc) cast iron disc, light, competitively priced design with improved cooling characteristics. Investigation of the cooling characteristics will be a subject of a separate article, with disc structural optimization being presented here.

The analysis is based on Lotus Elise S2 disc as this is already a high performance design, where disc rotor mass and rotating inertia reductions are very desirable and a relatively small cost increase is acceptable for a high performance vehicle. All 4 discs are identical for this vehicle but the analyses presented were conducted for the front disc which is subjected to higher mechanical and thermal loads. The disc is shown in Figure 1, with its main characteristics summarised in Table 1. This specific vehicle has been chosen for several reasons, its high performance, relatively low cost, its extensive use in track days and for racing, technically knowledgeable owners and considerable aftermarket offering of bespoke parts. Furthermore, the vehicle is relatively light, hence maximum braking torques are relatively low, and equally importantly, its disc top hat section axial offset is small (shallow), which reduces bending in the fingers which are to 
be created. Consequently, relatively low braking torque and fingers subjected to little bending maximize the chances of the concept to be successfully developed and productionized.
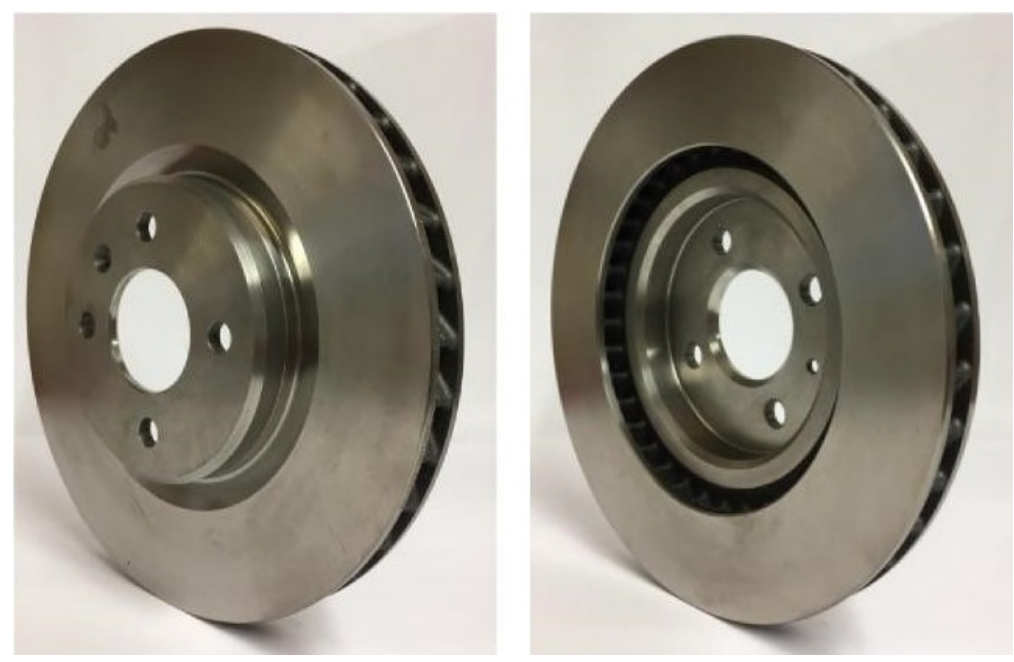

Figure 1. Standard Lotus Elise S2 brake disc.

Table 1. Characteristics of a standard brake disc for Lotus Elise S2

\begin{tabular}{|l|c|}
\hline Outer Diameter & $288 \mathrm{~mm}$ \\
\hline Inner Diameter & $182 \mathrm{~mm}$ \\
\hline Thickness & $26 \mathrm{~mm}$ \\
\hline Type and number of vanes & Curved, 37 \\
\hline Mass & $6.00 \mathrm{~kg}$ \\
\hline Convective heat dissipation area & $0.2495 \mathrm{~m}^{2}$ \\
\hline Radiative heat dissipation area & $0.1321 \mathrm{~m}^{2}$ \\
\hline
\end{tabular}

\subsection{Methodology}

In order to prove the validity of such a new concept, the fundamental analyses, experiments and validations will be conducted prior to embarking on an optimization process. For maximizing the effectiveness of the optimization process, all relevant literature has been studied in the detail and an outline of this review will be presented in 
the next section of the article. Modelling of cast iron will be also addressed and fundamental Finite Element (FE) models validated through 3 point bending tests conducted on the samples cut out from the disc. This will be followed by FE modelling of the disc and design synthesis of a baseline fingered disc. The disc will be instrumented and subjected to torsional loading to failure, in order to validate disc FE models and prove the feasibility of the fingered hub concept. Following this stage, an optimization process will be conducted, through shape and topology optimization procedures, in order to minimize disc stresses and mass.

\subsection{Literature review}

Numerous publications deal with disc design synthesis and analysis but such publications are typically related to thermal and Noise Vibrations and Harshness (NVH) characteristics and most approaches are not automated but follow step by step incremental improvements. For example, car disc studies are presented by Grieve et al. (1998) for lightweight disc under thermal load, Cho H. J. and Cho C. D (2008), investigate disc thermal optimization, Tang et al. (2018) deal with brake judder. In railway applications, Tirovic and Sarwar (2004) optimize wheel mounted railway disc, Dufrenoy and Brunel (2008) investigate axle mounted disc. Since most disc designs have solid hub, associated stresses due to mechanical loading are relatively low and dimensioning relatively straightforward. It was established that for the design with fingered hub, presented in this article, stresses created by mechanical loading can be very high and must be addressed first, before embarking on thermal and NVH considerations. Consequently, the research is focused on structural optimization techniques, and the related work published will be reviewed, staring with a selection of general structural problems applied to automotive applications and then focusing on brake specific articles. 
Structural optimization is a complex subject, considerably developed in recent years. Homogenization method is introduced by Bendsøe and Kikuchi (1988), where the authors aimed of generating both the optimal topology and the optimal shape of a structure. They created an alternative method, the homogenization, where the target was to optimally distribute the void in a rough block of space by boundary variations. In the first step a non-smooth estimate of the structural member is created and in the second step the design computed is optimized. Density method is introduced by Mlejnek and Schirrmacher (1993), where the Young's moduli of the elements are approximated by an energy approach. One of the early examples of topology optimization is given by Xie and Stevens (1993). By using the FE mesh created during the FE structural analysis, the authors imposed a rejection criterion (RC) based on the von Mises stress predicted values in order to neglect elements and only keep the ones necessary for the component's structural integrity. The $\mathrm{RC}$ includes a rejection ratio (RR) and an evolution ratio (ER). The software eliminates elements until it reaches a steady state according to the RR and thereafter it repeats the process until it satisfies the ER. Bakhtiary et al. (1996), presented different types of optimization available at the time: a) Sizing optimization; b) Shape optimization and c) Topology optimization. The sizing optimization adjusted the thickness or cross section of the finite elements. In shape optimization, two approaches were presented: the FE models based and the geometry based. In the first, the coordinates of the surface nodes are the design variables and are modified during the optimization. In the second approach, the design variables are the parameters of the geometry. In topology optimization, a $2 \mathrm{D}$ or $3 \mathrm{D}$ area is used with homogenous material distribution and depending on the boundary conditions the area becomes highly inhomogeneous in order for the optimal design to be created. 
Shin et al. (2002) describe a topology optimization method applied on the inner panel of an automotive door. By applying optimization steps, the weight of the inner panel was reduced by $8.7 \%$ and the total weight of the door was reduced by $3.2 \%$. Wang et al. (2004), used the method in an automotive body aiming to increase its rigidity. Laxman et al. (2009) started by categorizing and discussing the optimization techniques that can be used for the optimization of BIW vehicle structures in an attempt to determine the best use of each of these techniques. They concluding that, a) Topology optimization can determine the optimal material distribution within a package space for a set of boundary conditions; b) Sizing optimization can achieve the specified design target through modification of the properties of a part section; c) Topometry optimization is an advanced sizing optimization based on element sizing instead of property sizing.

Chiandussi et al. (2004), described an approach used to optimize the geometry of a rear suspension sub frame of a mid-size vehicle. They used the power-law approach, Solid Isotropic Material with Penalization (SIMP), of topology optimization and by calculating the Lagrange multiplier of the volume constraint before each new material density layout modification, they were able to indirectly control the density distribution of the finite elements. A transmission housing unit was optimized aiming to achieve weight reductions and maintain or increase the rigidity of the structure by Ogata and Hiraoka. (2005).

Strömberg (2010) worked on a method to automatically generate trade-off curves between compliance and weight when conducting numerical topology optimization. Cavazzuti, et al. (2011) presented an optimization approach applied on an automotive body of a mid-engine car. As a first step, they conducted topology optimization to monitor load paths and get the distribution of material density around the design domain. In the second step, they performed topometry optimization aiming in minor 
improvements from the first step in terms of parts that could be removed to reduce weight and components that should be re-oriented to maximize the stiffness response of the structure. In the final step, sizing optimization was incorporated to optimize the thickness distribution of structure's shell elements.

Deng and Lan (2016) investigated an efficient method to conduct topology optimization when multiple optimization targets are set. They used an automotive door glass lifter as an example, for which they set specific stiffness and NVH targets, which required a compromising programming method that accounted both the stiffness and NVH targets. By using the linearity-weighted-sum method they transformed the multiobjective optimization into a single optimization problem. Kumagai et al. (2016), applied topology optimization on a parking pawl component of an automatic transmission. They developed an algorithm that forced the optimization software to keep the outer dimension of the component's cross section constant to enable effective manufacturing.

Regarding the optimization of brake components, Edara (2006) optimized the performance and reduced the weight of a torque plate on a brake caliper of a heavy-duty commercial vehicle, decreasing its mass by $20 \%$. Goto et al. (2010), studied ways to reduce the squeal from automotive braking components, by applying the topology optimization to modify the caliper, pad carrier, pads and rotor in order to achieve the target eigenvalues. Sergent et al. (2014) conducted topology optimization aiming to reduce the mass of a fixed four-pot passenger car caliper. The caliper stiffness, i.e. deflections influencing brake fluid displacements were kept unchanged, ensuring the same brake pedal travel and feel. Two conceptual designs were created, with relatively minor differences in designable volume and boundary conditions, but both giving substantial yet relatively different mass savings of $19 \%$ and $28 \%$ in comparison with the baseline caliper. Wang et al. (2014), described the optimization of the lever component 
on an air braking system for heavy-duty vehicles. By setting the reduction of von Mises stresses and displacements as the optimization objectives, they achieved stress and displacement target values by marginally increasing the weight of the component. Inoue et al. (2015), investigated the possibility of using topology optimization to reduce the weight and improve the NVH performance in braking systems. Their optimization method improved the plural unstable modes and at the same time offered mass reductions. An interesting FE modelling approach in studying dry disc-pad contact analysis was presented by Belhocine and Omar (2017). This provides better understanding in component interaction and load transfer between the disc and pad, and ultimately further to the caliper.

\section{Cast iron characteristics and Finite Element modelling}

For brake disc manufacturing various grades of grey cast iron are used, with the emphasis on good thermal conductivity, stable friction, low wear and resistance to cracking. Mechanical (torsional) loading is not critical as disc solid hub can withstand relatively low associated stresses. For some applications, such as heavily loaded commercial vehicle brakes (such as SAF Holland, www.safholland.com), multi part discs are created, with the rotor being manufactured from grey iron (GI) and a fingered hub of spheroidal graphite cast iron (SG). No doubt that SG has far superior mechanical properties but also inferior thermal and friction characteristics to GI. Consequently, SG irons are rarely used for disc manufacture except for some railway and motorbike applications. They are, however widely used for caliper manufacturing. Regarding the disc rotors, in recent times, the manufacturers are often opting for higher graphite content grey irons, which have better frictional, thermal and NVH characteristics but wear somewhat faster. The disc considered here is manufactured from a proprietary grey cast iron. Due to relatively 
high graphite content such materials have complex stress-strain characteristics, different in compression and tension, with associated strain hardening and plasticity aspects. Some of the specifics of grey irons used for brake discs, stress-strain relationships and the associated modelling approaches are addressed by many authors, such as Barton (2018). Based on these considerations and proprietary data generated, a suitable cast iron material model in Abaqus FE code was created.

In order to test the validity of this model, prior to analyzing the actual disc, modelling was conducted on cast iron samples (cut from disc faces) subjected to 3 point bending. The results were compared with the test data obtained from 3 point bending tests. As disc fingers are to be loaded predominantly in bending, three-point bending loading case was considered most representative load case for model validations. The specimens were cut from both disc faces (inboard and outboard) in both directions (radial and circumferential) as shown in Figure 2. Two sample sizes were created, having

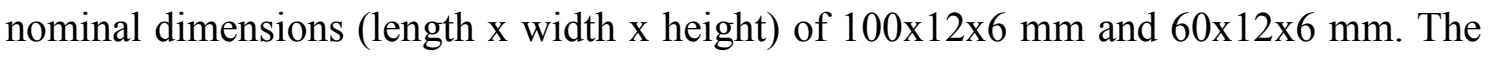
tests were conducted using Instron machine (model 5965, 5kN maximum force), with roller diameters of 8,5 and $3 \mathrm{~mm}$, and support span of 50 and $60 \mathrm{~mm}$. The mounting and loading components, set-ups and dimensions are supplied and recommended by the machine manufacturer. The test set-up is shown in Figure 3 and the corresponding FE model in Figure 4.

Force and displacement were measured using the transducer and load cell which are part of the Instron machine (accounting for machine deformation). In addition, Digital Image Correlation (DIC) method was used to monitor strain changes during loading for the entire sample side face. It can be noted in Figure 3 that the light used is monochromatic green. This provided valuable information about sample behaviour and enabled comparisons with FE strain results for the entire specimen side face. 


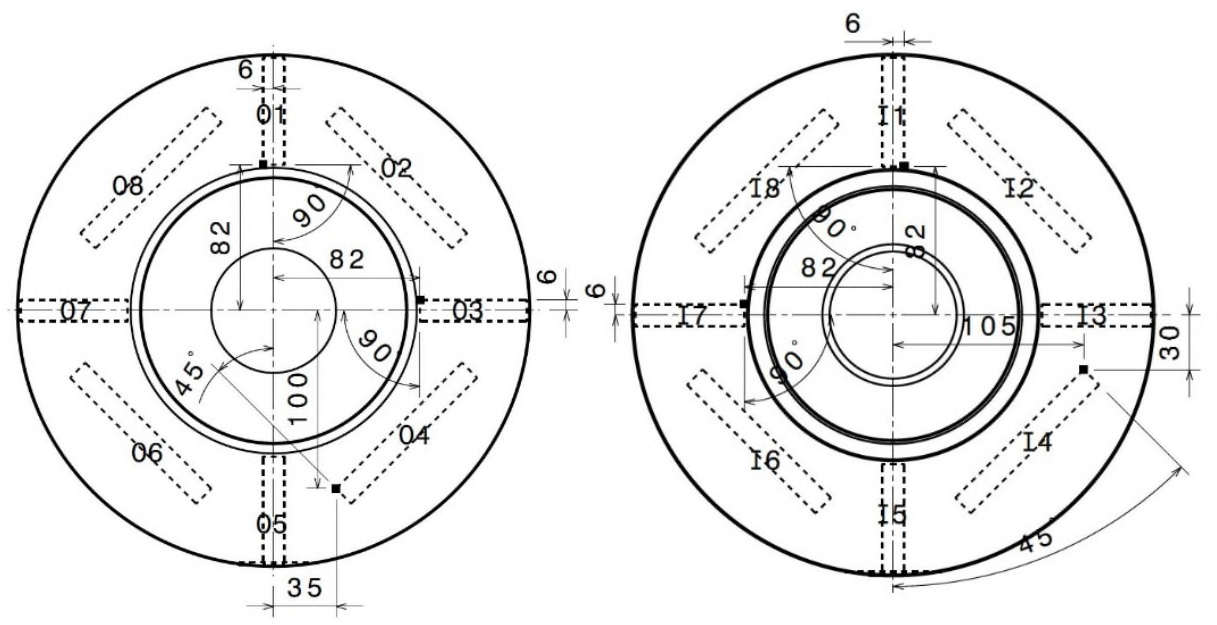

(a)

(b)

Figure 2. Specimens machined from disc faces: (a) inboard and (b) outboard.

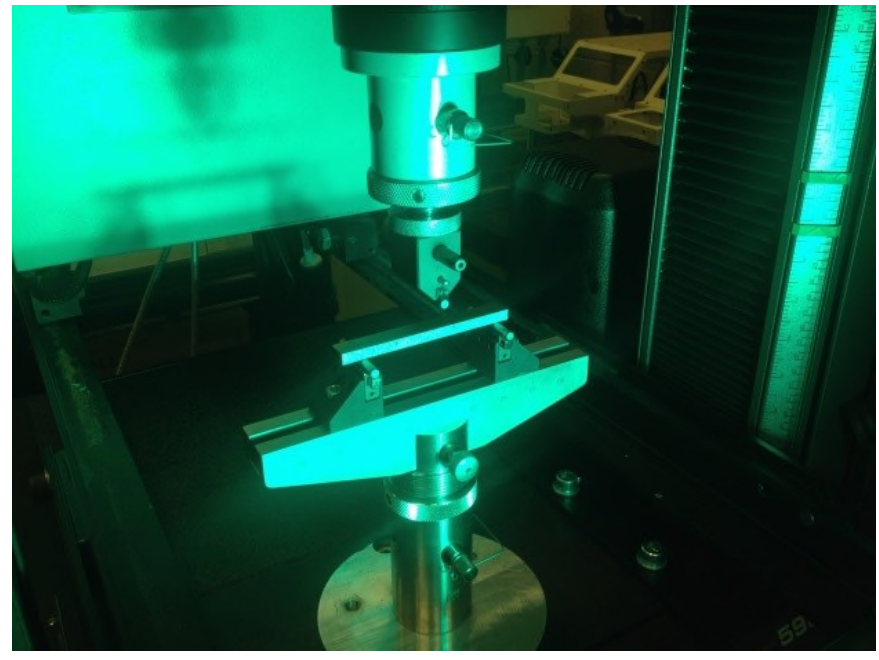

Figure 3. Three-point bending test.

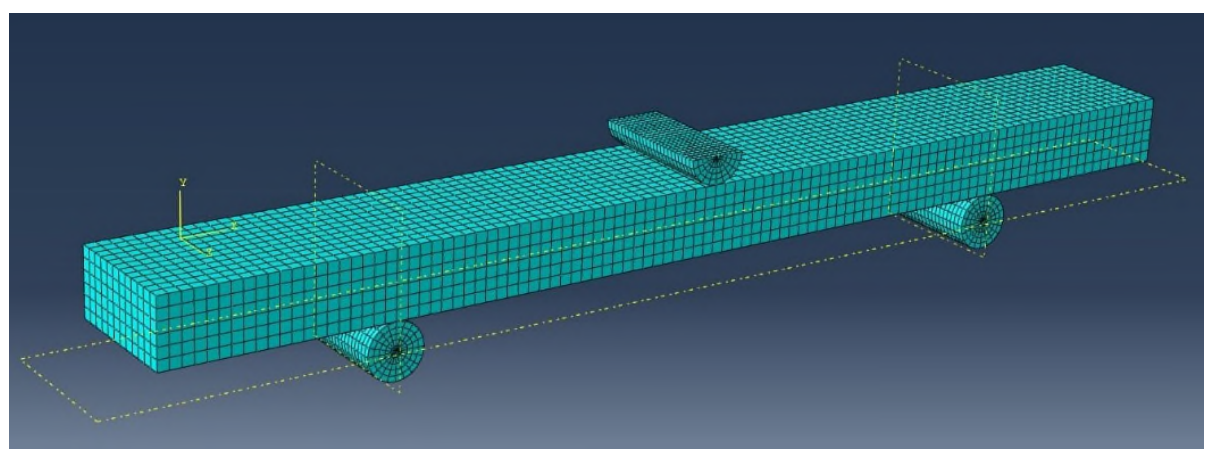

Figure 4. Three-point bending FE model. 
As was expected, cast iron demonstrated non-linear characteristics shown in Figure 5 for Specimen I2, for load input at constant speed of $4.5 \mathrm{~mm} / \mathrm{min}$. All specimens exhibited very similar characteristics, with expected but small differences due to variations in cast iron properties, geometrical imperfections of the samples, influence of friction at the contact with the rollers, the difference in sample sizes, loading length etc. For the same specimen length and distance between the rollers, the measured forces causing specimen failure were very close, within the $\pm 4 \%$ of the average value. No specific differences could be related to the position on the disc from where the specimen was cut. This is in respect to all three aspects: the specimen 'absolute position', the disc face (inboard/outboard) and orientation (radial or circumferential). It should be noted that car discs are cast vertically, and some sources quote differences in properties due to such casting method (related to the material solidification) and subsequent heat treatment processes.

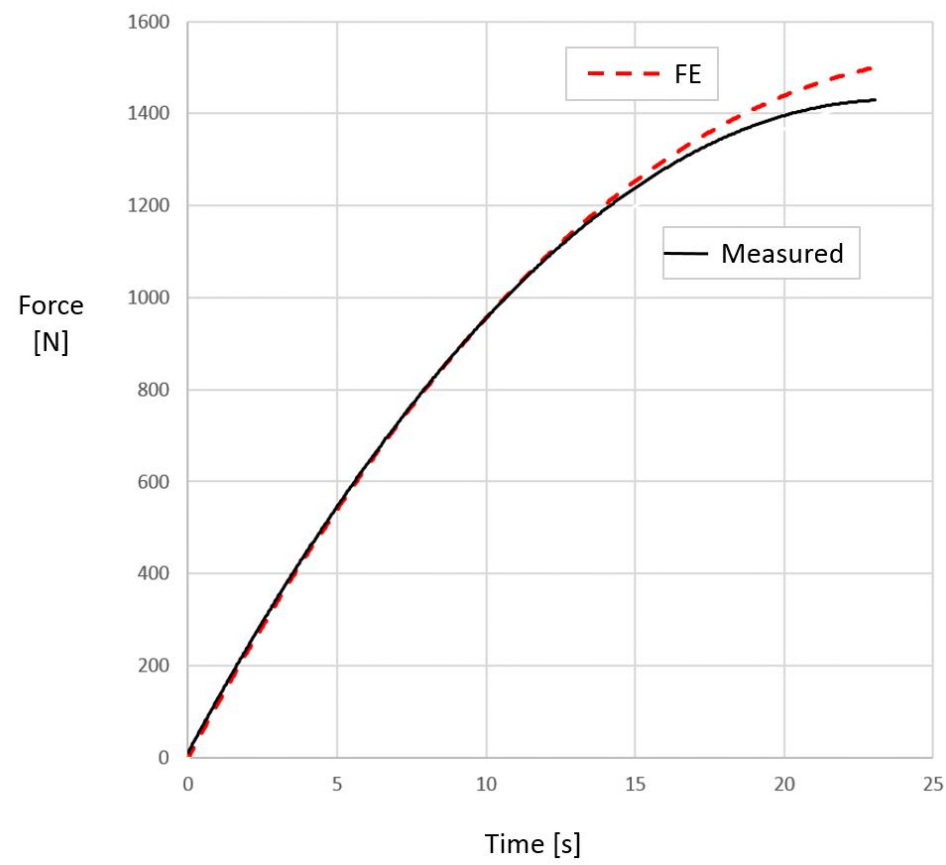

Figure 5. Specimen I2 response: FE prediction and measured values. 
The input data for Finite Element modelling of cast iron was propriety information obtained from a vehicle manufacturer. The data was generated by an approved test house, using separate samples and providing accurate true stress - true strain characteristics. The FE results of the 3 point bending model (Figure 4) agreed very well (Topouris, 2017) with the measured values (Figure 3), as shown in Figure 5. It can be noticed that FE modelling under predicts the force at the beginning of the loading phase and over predicts at later stages, resulting with a maximum force overestimation by around $5 \%$, which is considered acceptable. Figure 5 shows measured results for Specimen I2, with other specimens showing very similar relationships. Following this model validation, the analysis of the brake disc was conducted. It should be pointed out that cast iron properties can sometimes considerably vary, even at room temperature, as a result of many factors, from composition, manufacturing methods employed, heat treatment etc., with some aspects addressed in detail by Vadiraj and Tiwari (2013).

\section{Establishing the baseline fingered hub disc design}

\subsection{Finite Element modelling}

Using the cast iron properties established and validated FE modelling approach shown in previous section, several fingered disc designs were created, analysed and compared. In the first instance, the designs were to be suitable for machining from a standard Lotus Elise S2 disc presented in Figure 1 but also for casting in later development stages. Numerous FE analyses were run for the discs subjected to clamping and torsional loading, with particular attention on mesh sensitivity and boundary conditions. In order to correctly load the disc, pad models were also created and the actuating forces applied

over the backplates, in their contact areas with caliper pistons, with corresponding reaction and friction forces being generated at the friction interface and pad/caliper 
abutments. It was proven that there is no need to include caliper in the model, for as long as the pad backplate/caliper contacts were suitably modelled. Disc rotation was also necessary to model in order to ensure realistic loading and accurate results.

Figure 6a shows the FE model, also indicating pad backplate contact areas with caliper. Figure $6 \mathrm{~b}$ details disc FE mesh which combines C3D8R elements of approximately $1 \mathrm{~mm}$ of size on the spokes (fingers), with the rest of the disc was meshed with tetrahedra C3D4 elements of $3 \mathrm{~mm}$ size applied by using the free mesh technique on the areas of low stress. The analyses conducted were non-linear elasto-plastic and the loading corresponded to the braking torque of $882 \mathrm{Nm}$ that was representing a severe braking at the limits of adhesion for the front axle of Lotus Elise.

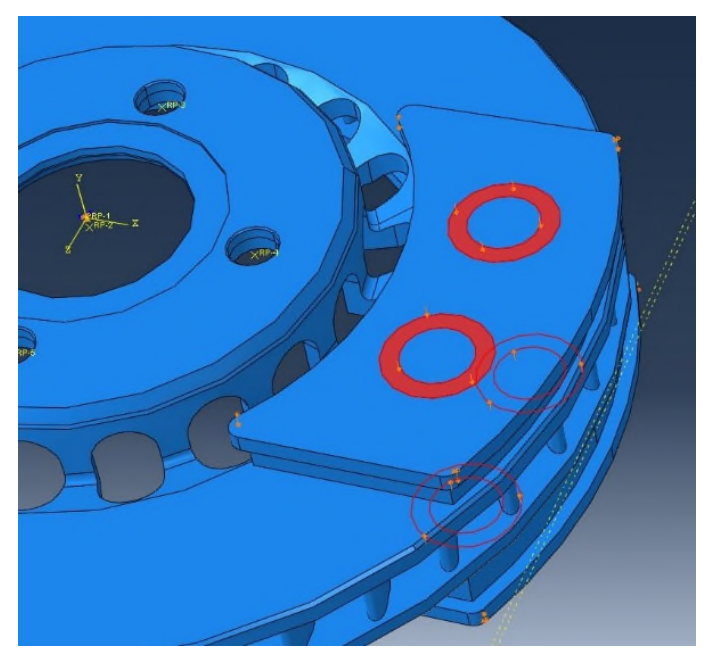

(a)

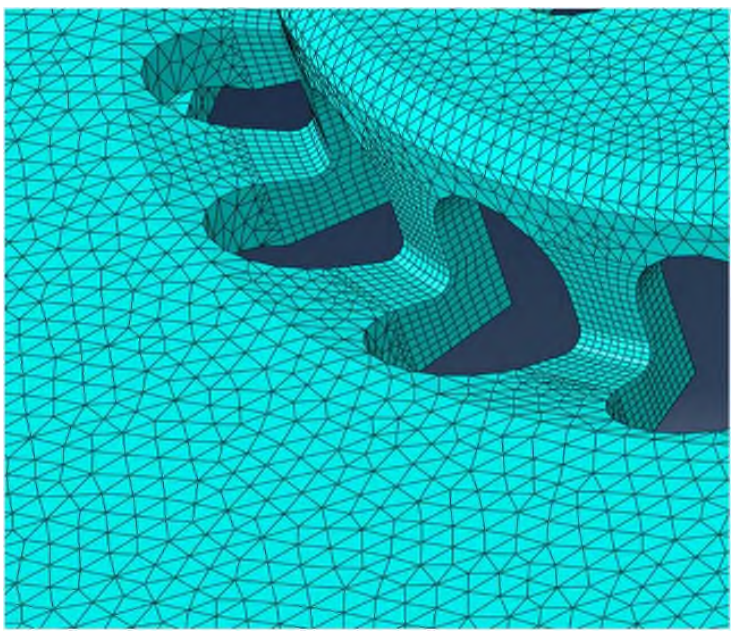

(b)

Figure 6. Brake FE modelling: (a) disc and pad assembly and (b) disc mesh detail.

Figure 7a shows von Mises and 7b Maximal principal stresses, in the regions where they reach maximum values - in the proximity of the caliper. 


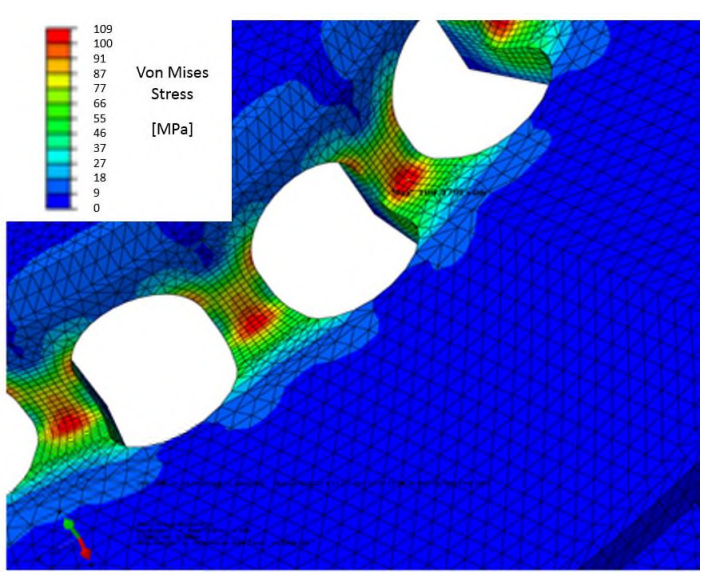

(a)

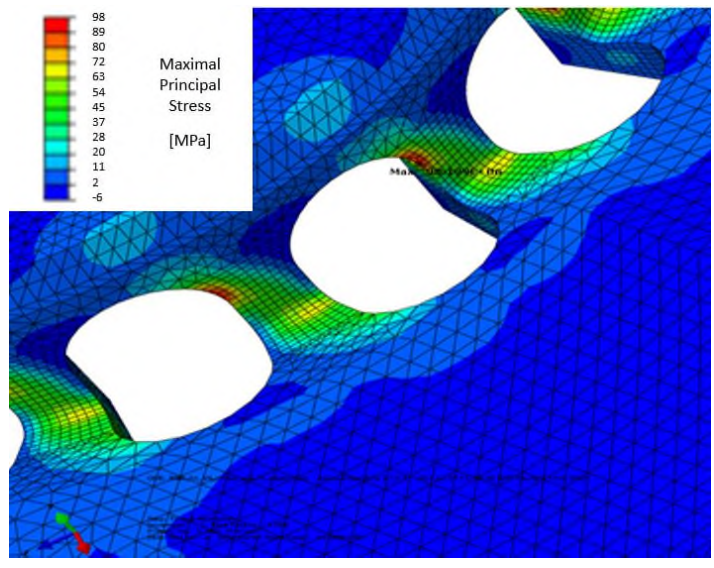

(b)

Figure 7. Disc stresses: (a) von Mises Stress and (b) Maximum Principal Stress.

\subsection{Disc manufacture, testing and validation}

A standard Lotus Elise S2 disc was used to manufacture the newly established baseline fingered design by machining out sections of the disc top hat section (hub), as shown in Figure 8. It can be noticed, when comparing with the standard disc (Figure 1) that the disc has identical friction surfaces and other features. Machining out the 'pockets' from disc top hat has reduced disc mass from $6 \mathrm{~kg}$ to $5.5 \mathrm{~kg}$, a decrease of about $8.5 \%$. The pockets created also provide very suitable air paths for improving disc cooling. Disc wetted area reduced only slightly from the original values (see Table 1), to $0.2372 \mathrm{~m}^{2}$ and radiative area to $0.1217 \mathrm{~m}^{2}$.
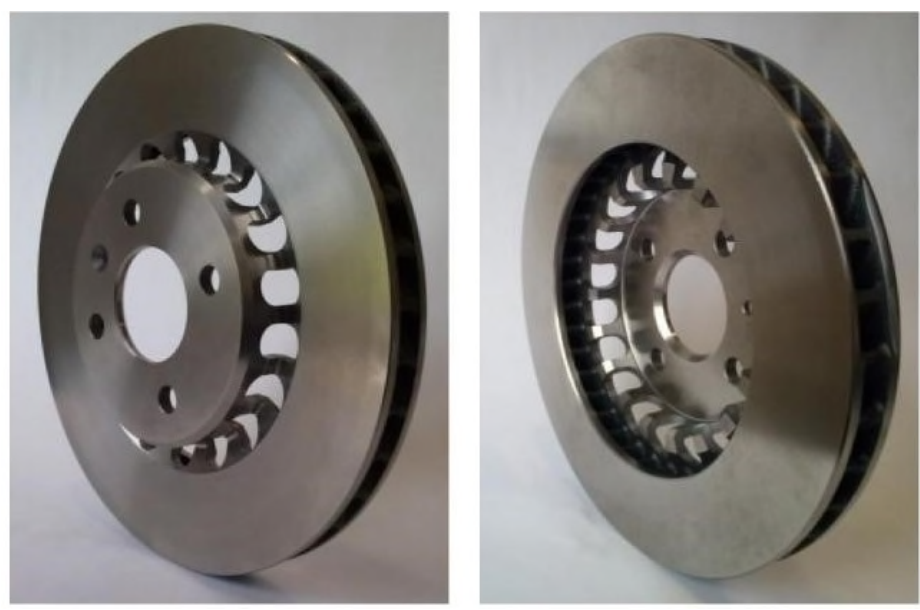

Figure 8. Newly established baseline fingered disc design. 
Prior to torsional testing, the disc was instrumented with a range of strain gauges, individual, rosette and ladder type in order to monitor strains in critical areas. An optical Fibre Bragg Grating (FBG) sensor was installed too, which proved to be very useful. Figure 9 details a single gauge (a) and FBG sensor installation (b).

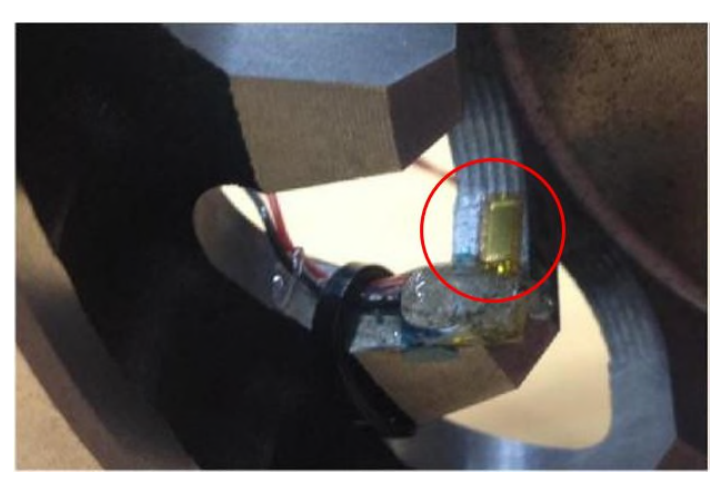

(a)

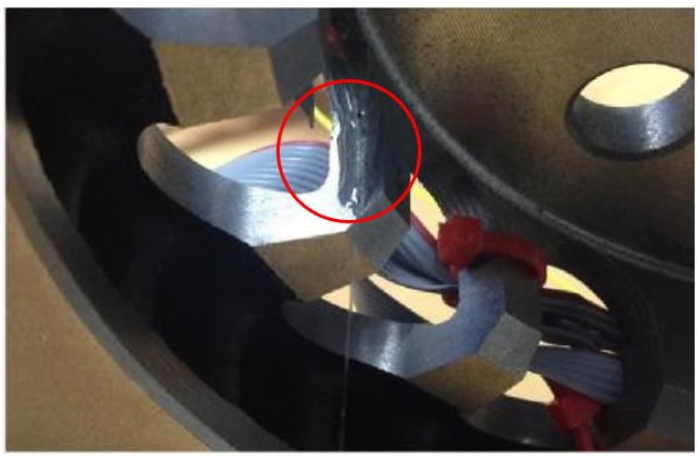

(b)

Figure 9. Disc instrumentation: (a) Single strain gauge and (b) FBG sensor.

The disc was installed into a purpose built static torque rig which enabled suitable brake actuation using a hydraulic caliper and friction pads, as well as application of a static torque. Figure 10a shows the rig, the disc (1) with caliper (2) actuated via a hydraulic system (3). The loading arm (4) is $1 \mathrm{~m}$ long (from the centre of disc axle to the centre of the weight link) and weights (5) are used to generate the torque. The arrangement enabled very accurate and constant torque loading by adding suitable weights (masses 5) and ensuring the loading arm (4) remains horizontal. As expected, the hydraulic pressure had no influence on the results, however to ensure the disc does not slips/rotates, the measurements were performed for the pressure of 100 bar, which corresponds to the maximal operating pressure. The torque was gradually increased by adding masses (5), up to $100 \mathrm{~kg}$, corresponding to $981 \mathrm{Nm}$ of torque, which is in excess of $882 \mathrm{Nm}$ considered to be the maximum value likely to be experienced at the front 
wheels prior to wheel locking (on dry road and with road tyres). This loading phase was followed by off-loading where the masses were gradually removed. The strains were logged throughout both these phases. The loading arm was then unbolted, the disc rotated by $90^{\circ}$ and re-bolted. In such a manner the strains were measured in 4 distinctive circumferential positions. These 4 positions are marked as ' 0 Degrees', '90 Degrees, '180 Degrees' and '270 Degrees' on the disc CAD model in Figure 10b.

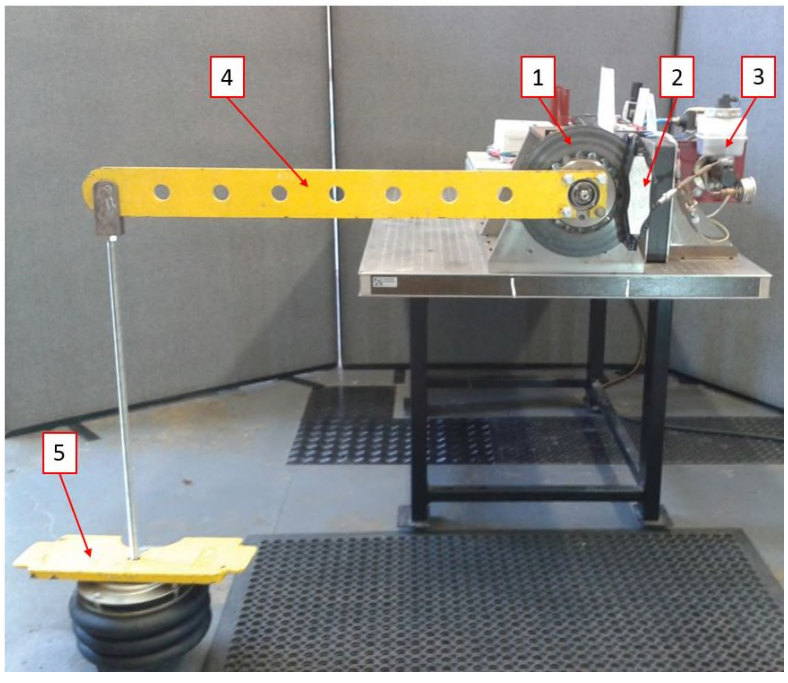

(a)

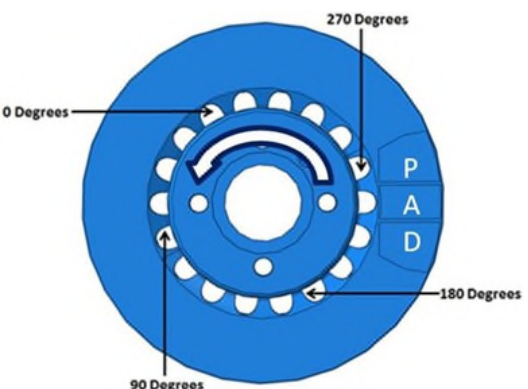

(b)

Figure 10. Torsional disc loading and strain measurements: (a) the Rig and b) Positions.

Figure 11 shows strain results obtained using a strain gauge and FBG sensor (See Figure 9) during loading and off-loading, together with FE strain prediction for the same, '270 Degrees' position, which corresponds to the highest stresses (in the proximity to the caliper). The measurements correlate very well with FE prediction, with the best, almost perfect match with the optical sensors during the loading phase. The graphs also show relatively pronounced strain hysteresis. Obviously, during an actual braking, the disc rotates and individual fingers will change relative position to the caliper, causing the strains to cycle. 


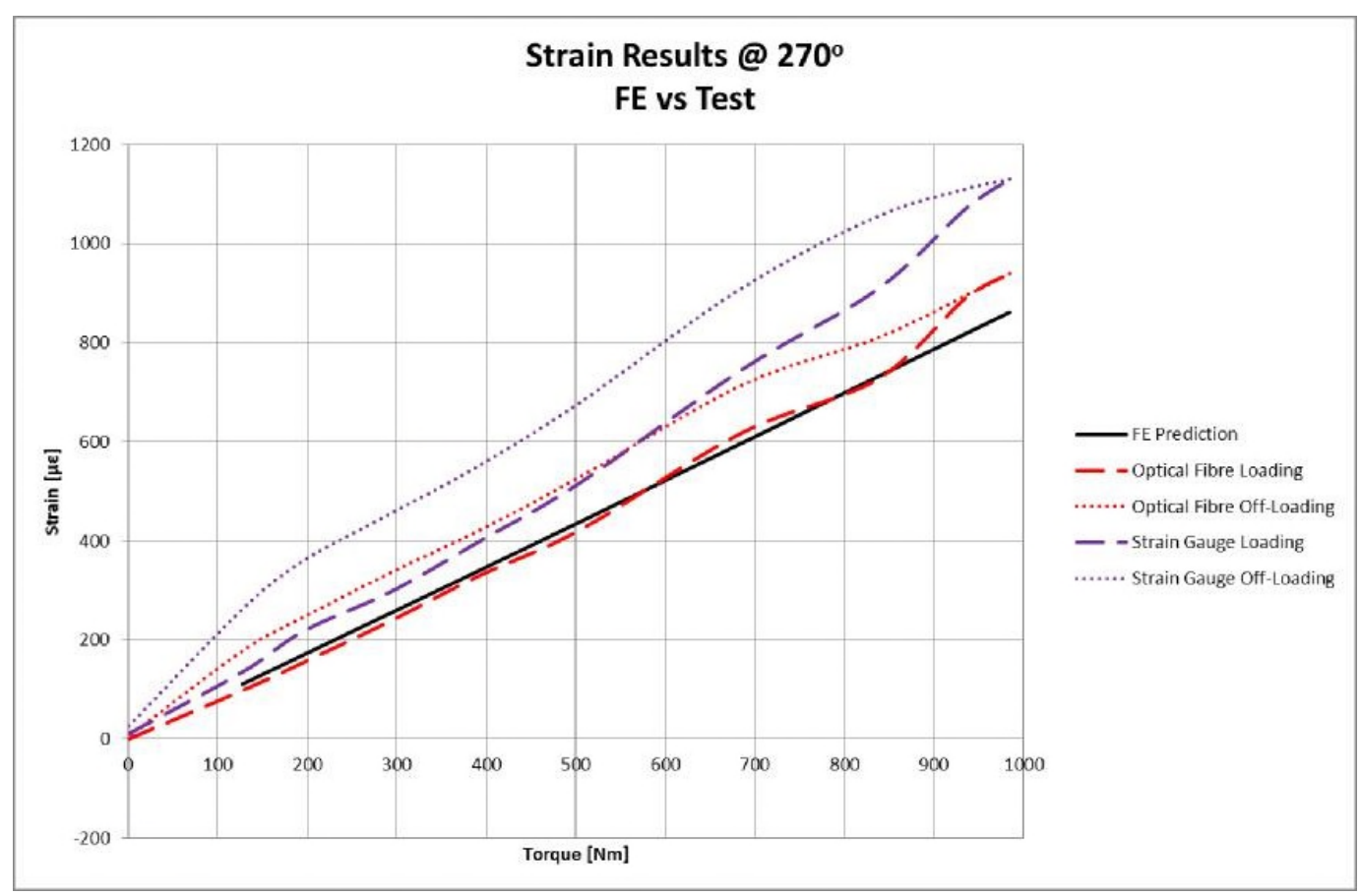

Figure 11. Strain measurements and FE predictions at $270^{\circ}$ position.

Following a successful validation of the FE model, disc loading was increased up to the point of failure. In order to achieve higher torque values, two aspects of the test setup had to be modified. Firstly, the masses required were getting too high and they were no longer used but the drop link was connected to a turnbuckle and a force transducer, with the bottom end anchored to the floor. Higher torque required higher brake actuating forces but substantial increase of hydraulic pressure was unfeasible, therefore a steel pin was inserted into the disc ventilation channel from the outer diameter, locking the disc against the caliper. The force (torque) was gradually increased using the turnbuckle until the disc failed. As FE results indicated (Figure 7b), the failure occurred in the fingers, in the regions of maximum principal stresses, as shown in Figure 12. The torque value reached $2481 \mathrm{Nm}$, which is almost 3 times higher value than the maximum torque likely to be expected in normal vehicle road use. This 'reserve' in torque builds further confidence in feasibility of the proposed fingered design concept. The baseline fingered disc design (shown in Figure 8) can now be subjected to structural optimization. 


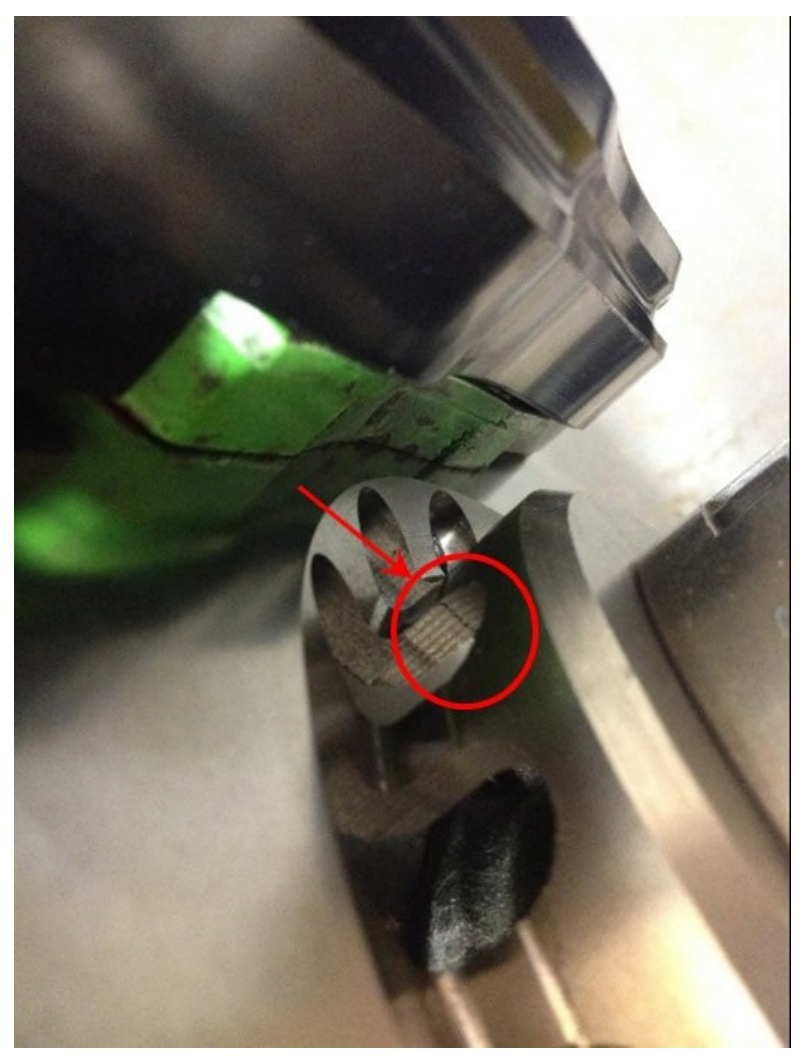

Figure 12. The area of disc fingers failure (crack circled).

\section{Structural optimization}

Following from the previous findings, it was observed numerically and experimentally that the Maximum Principal stress criterion on the fingers will cause the fracture of the disc. Therefore, the first optimization target is to reduce the levels of Maximum Principal stresses on disc fingers. The second optimization target is to investigate the possibility of further mass reduction, by removing material from areas where there are no 'load paths'. In order to achieve both optimization targets, the techniques of Shape Optimization and Topology Optimization were utilised, each emphasising only on one target. Shape Optimization was used to minimize the Maximum Principal stresses on the fingers and Topology Optimization was employed to reduce the mass of the disc. The FE solver used for the aforementioned techniques was OptiStruct, the pre-processing software was 
HyperMesh and the post-processing software was HyperView. All these packages were provided by Altair Engineering.

\subsection{Shape optimization}

The principle behind the Shape Optimization for a 3D model is that for a given set of boundary conditions, the FE solver moves the element nodes into the three dimensional space in order to achieve the optimization target set by the user. Thus, with minor geometric adjustments, the desired results are achieved. As with any optimization technique, the influencing parameters are:

- The definition of the Design and Non-Design spaces,

- The type of elements used,

- The material properties,

- $\quad$ The boundary conditions applied (the loads and the restrains),

- The optimization objectives and the optimization constraints.

All the above parameters will be presented and discussed thoroughly as they were vital to the modelling being correctly and efficiently conducted.

The Design and Non-Design spaces are defined in order to specify the area where the solver has to conduct the optimization process. As it is shown in Figure 13, the Design space was the area of the disc fingers. All the other areas, the hub, the friction faces and the cooling vanes, were considered not to be influential for the reduction of Maximum Principal stresses in the fingers and they were specified to be Non-Design space.

Following the modelling approach of the mechanical simulations and aiming to capture the stress gradients with as great accuracy as possible, in the Design space the element size was set to $1 \mathrm{~mm}$. In the Non-Design space, the elements size was $3 \mathrm{~mm}$, ensuring shorter computational times. This resulted in the total number of elements being 
851,400 , of which 425,695 were in the Design space, and the total number of nodes being $210,156$.

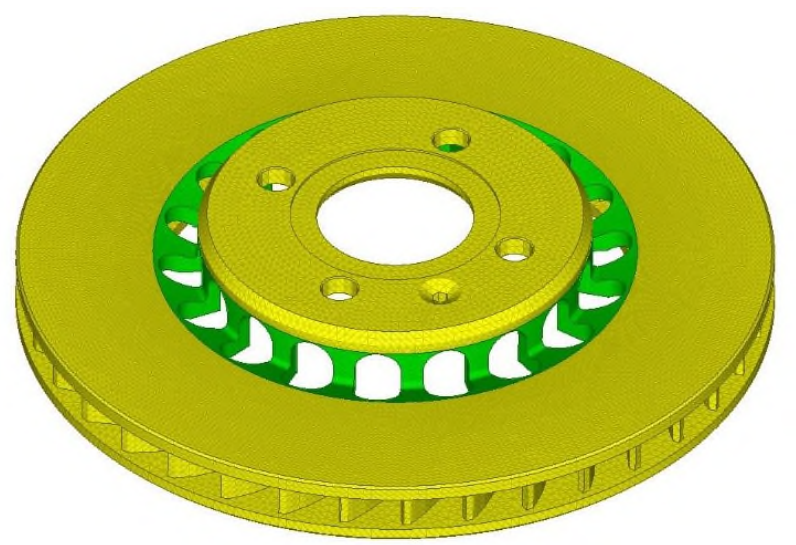

Figure 13. Design (fingers) and Non-Design spaces (flange and friction ring).

For the Shape Optimization study, simplified material properties were selected having in mind two major aspects. The first and most crucial was to use linear material properties. As shown in previous analyses when the maximum braking torque of $882 \mathrm{Nm}$ is applied, the highest von Mises and Maximum Principal stresses are below the yield threshold of the material. In addition, simplified material properties result in faster solutions.

The boundary conditions were applied in accordance with the previously shown analyses, with the generated torque of $882 \mathrm{Nm}$. In order to allow only the rotational degree of freedom around the axis of the disc, all the nodes located on the top hat flange were connected to a single 1D point element in the middle of the top hat by rigid 1D elements. Whereas previously only a part of the friction faces, in the contact with pads was restrained, for the Shape Optimization the entire friction surfaces were restrained using Encastré boundary condition. This approach is necessary for the solver to create circumferentially symmetric geometry, i.e. for all fingers to be the same. Otherwise, the optimized design would have stronger fingers in the proximity of the pad/caliper than in other areas. This would be obviously wrong, as the disc rotates and all fingers change 
relative position to the caliper/pads. The final step in setting up the Shape Optimization was to create the optimization objectives. There was only one objective in the case studied - to minimize Maximum Principal stress in the finger areas of the disc.

Prior to running the optimization procedure, FE analysis for the baseline fingered disc was conducted using OptiStruct package for the same mesh, material characteristics and boundary conditions as used with Abaqus solver. OptiStruct modelling was linearelastic, with Abaqus being non-linear elasto-plastic. As mentioned earlier on, within the working envelope (braking torques under $882 \mathrm{Nm}$ ), there was no plasticity detected by Abaqus software or the strain measurements. Such approach was necessary to ensure OptiStruct is giving sufficiently close stress predictions to Abaqus in order for the optimization approach to be valid. As shown in Table 2, the difference to Abaqus maximum principal stress is under $5 \%$, which is considered acceptable (all stresses are shown at their maximum, for $270^{\circ}$ position as shown in Figure $10 \mathrm{~b}$ ). The optimization analysis ran very effectively, requiring 5 iterations which only took about 3 minutes.

The results presented in Table 2 show substantial drop in maximum principal stress after the shape optimization, from $103 \mathrm{MPa}$ to $70 \mathrm{MPa}$, equalling 32\% relative reduction. This is a considerable achievement, with the safety factor increased by 1 unit. The safety factor has been established as the ratio of the stress at the torque which would fracture the fingers to the maximum braking torque realistically expected on the vehicle (882 Nm), which is limited by the tyre/road adhesion.

Such stress reduction was achieved with relatively minor changes in finger geometry. There were only slight adjustments in the position of nodes conducted by the solver. Contour plots in Figure 14 show the shape change magnitude. The majority of the nodes were moved by less than $1 \mathrm{~mm}$. Only in the middle of the finger swan neck area, there is a summit with the nodes moved by up to $1.55 \mathrm{~mm}$. 
Table 2. Shape optimization results.

\begin{tabular}{|c|c|c|c|}
\hline Model & $\begin{array}{c}\text { Max. Principal Stress } \\
{[\mathrm{MPa}]}\end{array}$ & $\begin{array}{c}\text { Difference } \\
{[\%]}\end{array}$ & $\begin{array}{c}\text { Safety Factor } \\
{[-]}\end{array}$ \\
\hline Baseline - OptiStruct & 103.0 & - & 2.43 \\
\hline Baseline - Abaqus & 98.2 & -4.6 & 2.55 \\
\hline $\begin{array}{c}\text { Shape-Optimized - } \\
\text { OptiStruct }\end{array}$ & 70.0 & -32.0 & 3.57 \\
\hline
\end{tabular}

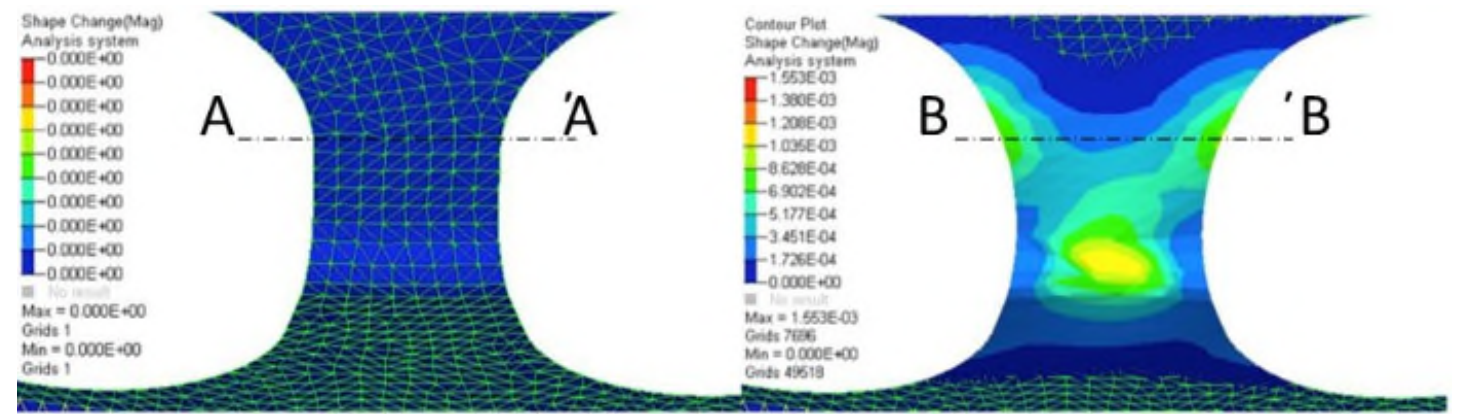

(a)

(b)

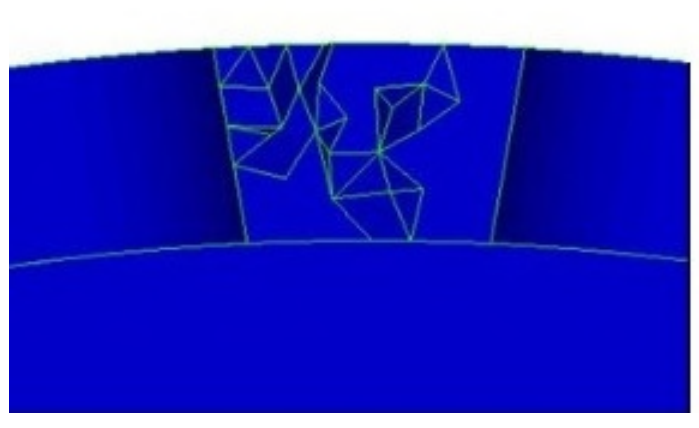

(c)

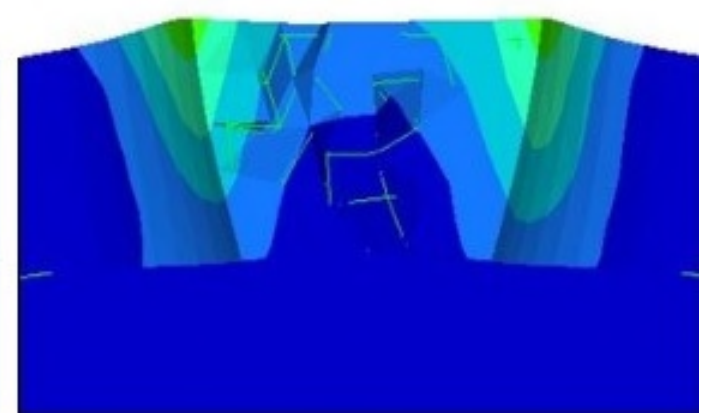

(d)

Figure 14. Shape Optimization Effect on the Fingers: (a) Baseline shape; (b) Optimized shape; (c) Cross section A-A; (d) Cross section B-B

The optimization had resulted in each finger to be thickened, but mostly on the outboard side of the rotor. The inboard geometry mainly remained unaltered with the 
exception of the finger areas close to the hub as illustrated in Figure 15. This addition of material had minimal influence on increase in disc mass of only $0.4 \%$.

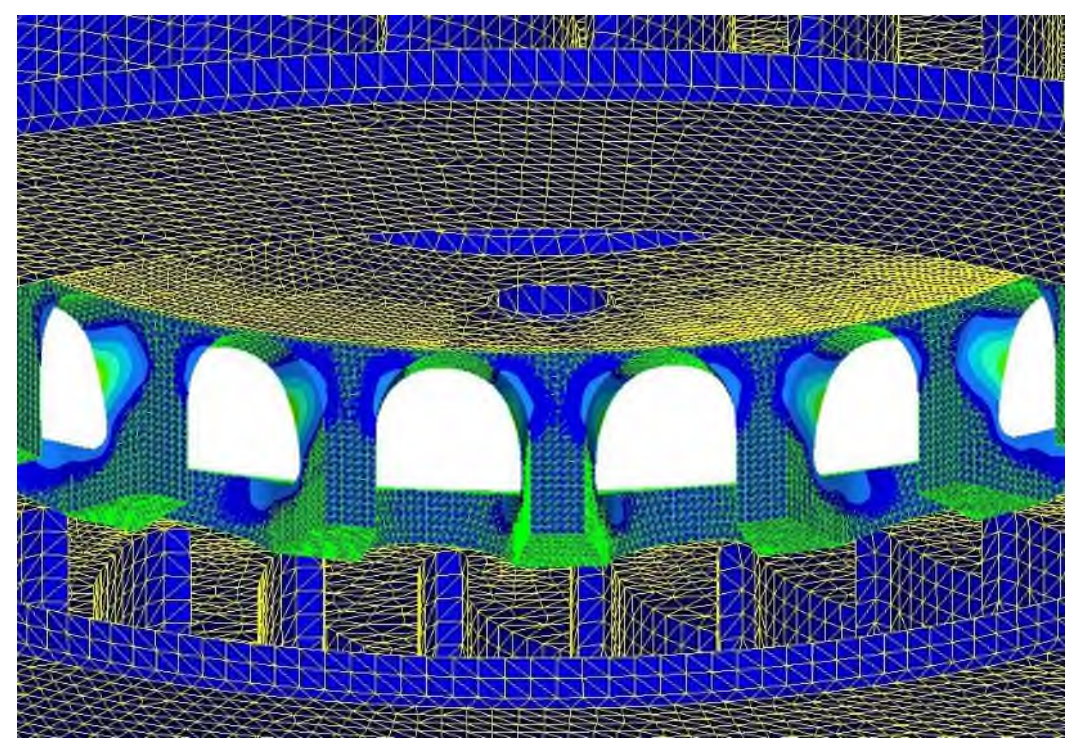

Figure 15. Shape Optimization Effect on the Fingers - Inboard Side View.

\subsection{Topology optimization}

After achieving lower Maximum Principal stresses in the fingers through Shape Optimization, the next step in the structural optimization process was to investigate the possibilities in reducing disc mass, by employing Topology Optimization. The assignment of Design and Non-Design spaces was exactly the same as in the previous step with the material properties and the boundary conditions being no exception. Topology Optimization required two parameters to be defined in order for the process to converge:

- The optimization constraint,

- The optimization objective.

Since the Maximum Principal Stress results from the previous step were satisfactory, it was decided to set the Maximum Principal stresses as the optimization constraint. Having constrained the stresses, the optimization objective selected was to minimize the volume of the Design area, i.e. disc mass. 
The analysis time lasted approximately 4 minutes and required a total of 11 iterations to successfully converge. By visualising the results in HyperView, the areas where material was removed by OptiStruct can be identified. The simulation outcomes are illustrated in Figures 16, 17 and 18, based on their isodensities (being 0.15, 0.30 and 0.50 respectively). It can be seen that the bulk amount of material removed was in the areas where the fingers are connected to the (i) hub, connected to the (ii) friction faces of the disc and (iii) at the rear and bottom part of the fingers themselves. Additionally, small portions of material were removed from the upper areas of the fingers close to the flange on the outboard side of the disc. By analyzing the results and figures above and consulting relevant literature it was considered most appropriate to choose the shape when the isodensities were equal to 0.30 , as the structural integrity is maintained, the manufacturing is feasible and there are some mass savings.

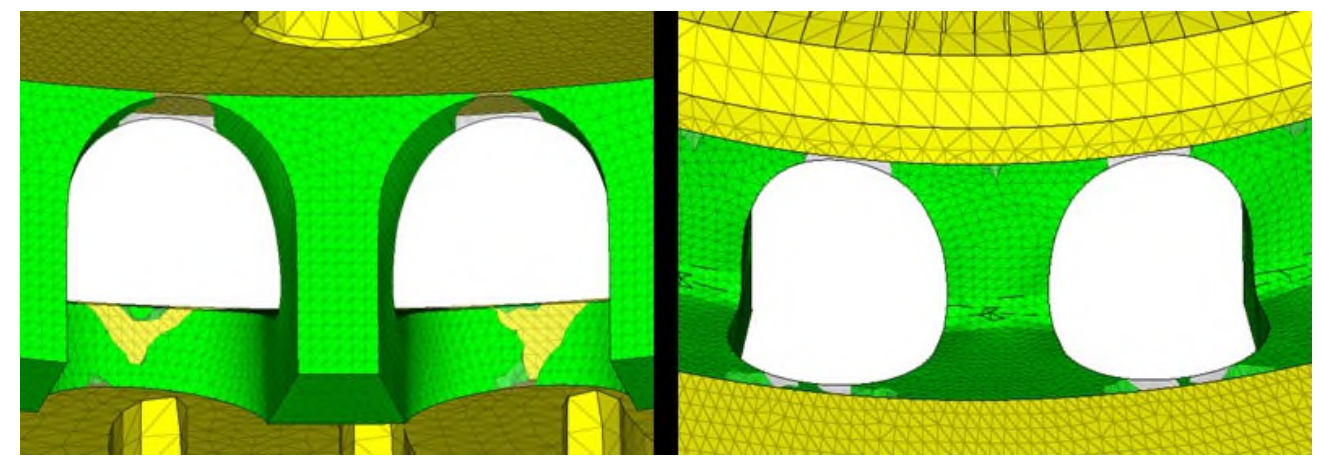

(a)

(b)

Figure 16. Topology Optimization, Isodensity $=0.15$ : (a) Inboard and (b) Outboard Side

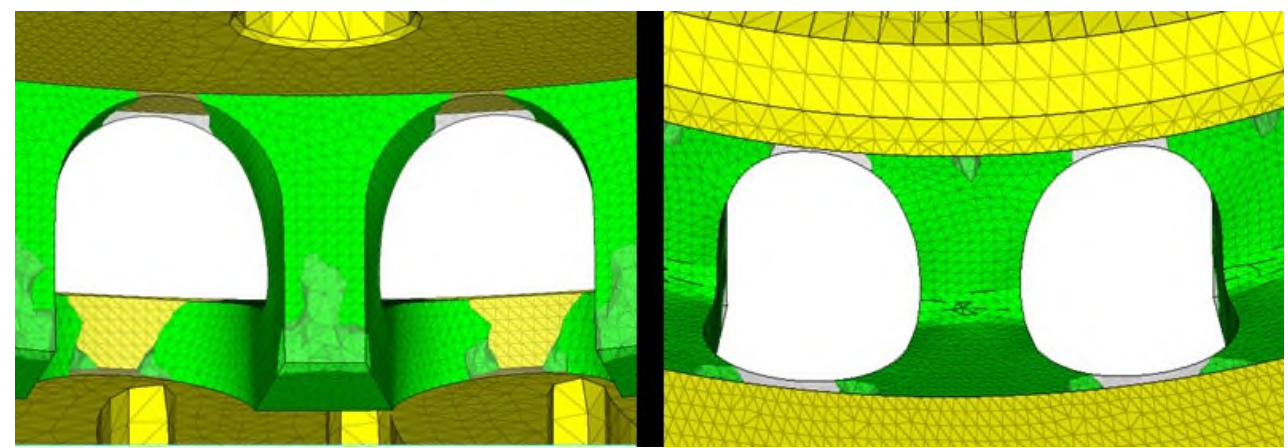

(a)

(b)

Figure 17. Topology Optimization, Isodensity $=0.30$ : (a) Inboard and (b) Outboard Side 


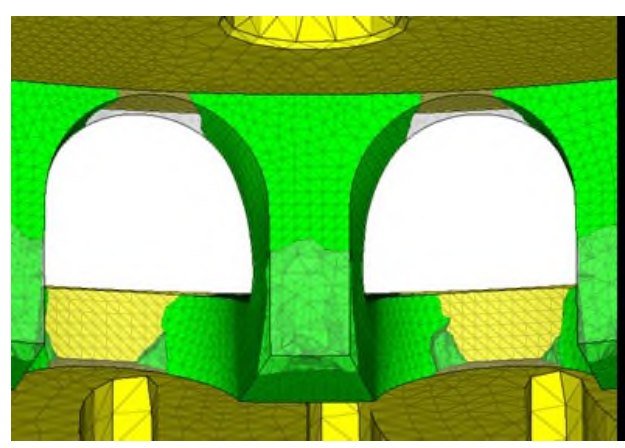

(a)

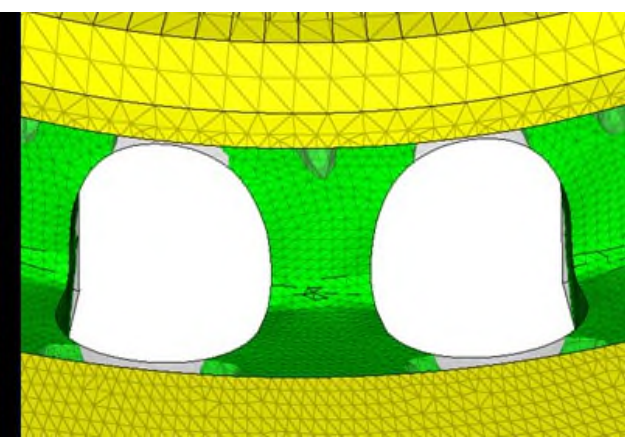

(b)

Figure 18. Topology Optimization, Isodensity $=0.50$ : (a) Inboard and (b) Outboard Side With the Shape Optimization, that preceded the Topology Optimization, the total volume of the disc was increased since the fingers became slightly thicker. With the conduction of Topology Optimization, and the decision to keep the results at 0.30 isodensity, the total disc volume including the Design and Non-Design spaces, was reduced by $1.1 \%$ compared to the initial volume of the baseline design and by $1.5 \%$ compared to the volume of the disc after the Shape Optimization. It should be kept in mind that the fingers are already slender and the total Design Volume is relatively small, hence substantial mass reductions cannot be expected. The volume reduction percentages and the gains in terms of mass are summarised in Table 3, starting with the standard disc currently installed on the vehicle. CAD model of the final, optimized disc design is shown in Figure 19.

Table 3. Effects of Structural Optimization.

\begin{tabular}{|c|c|c|c|c|}
\hline \multirow{2}{*}{ Disc Model } & \multirow{2}{*}{ Mass [kg] } & \multicolumn{3}{|c|}{ Relative Difference [\%] } \\
\cline { 3 - 5 } & & to Standard & to Baseline & $\begin{array}{c}\text { to Shape } \\
\text { Optimized }\end{array}$ \\
\hline Standard & 6.00 & - & - & - \\
\hline Baseline (fingered) & 5.50 & -8.30 & - & - \\
\hline Shape Optimized & 5.52 & -7.97 & +0.4 & - \\
\hline Topology Optimized & 5.44 & -9.30 & -1.1 & -1.5 \\
\hline
\end{tabular}




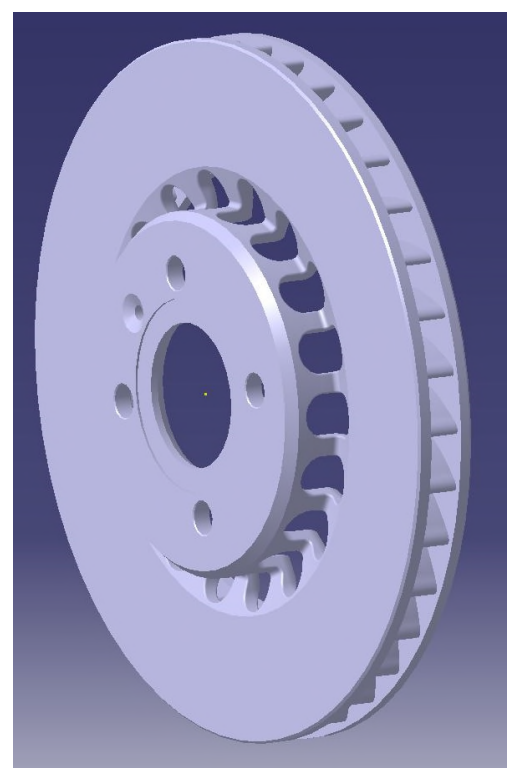

a)

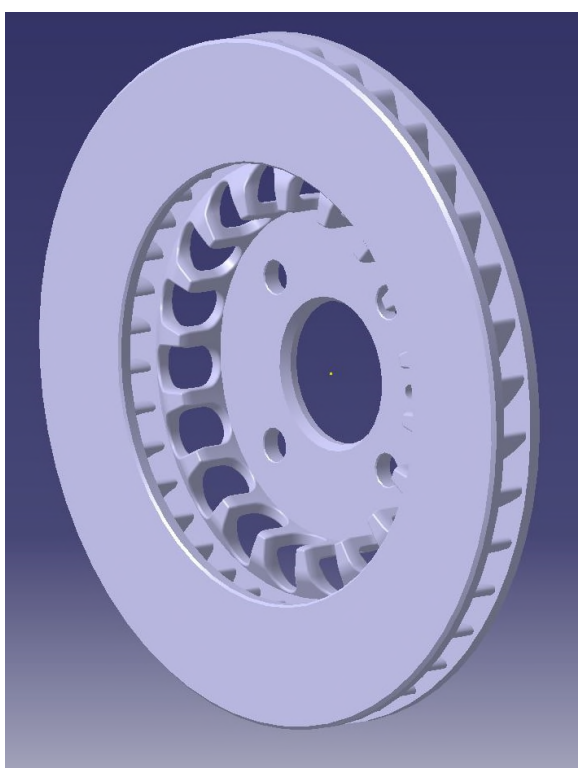

b)

Figure 19. CAD model of the optimized disc: (a) Outboard and (b) Inboard view

\section{Discussions, Conclusions and Further work}

The main motivation for the work conducted was to create a lighter disc with better heat dissipation characteristics. The design approach was directed towards a fingered hub (top hat) design, which will reduce mass but maintain rotor thermal capacity and improve air entry on both disc faces and within ventilated channels. The choice of the vehicle (Lotus Elise S2) was driven by its high performance, low mass and favourably small disc top hat offset. Initial fingered design bas created using a standard disc and extensive FE modelling, with the fingers created by machining (milling out) pockets in the disc top hat section. Such a design was instrumented and torsionally tested to failure, which proved to have a considerable strength. Additionally, three-point bending tests gave deeper insight into the cast iron properties, with all these activities providing a solid base for conducting a comprehensive optimization procedures.

Through Shape Optimization and Topology Optimization procedures the full potential of the design have been accomplished. Shape optimization enabled reduction of 
maximum principal stress by $32 \%$, considerably improving disc torsional strength with practically no mass increase (only $0.4 \%$ ). The safety factor in torsion achieved the value of 3.57. Topology Optimization enabled further, though small mass reduction $(1.5 \%)$ whilst maintaining low stress levels. The analyses and tests clearly demonstrated that a monobloc, fingered disc design is possible to achieve, with mass reduction of just over 9 $\%$ to the original design, whilst maintaining structural integrity. All analyses presented in this article relate to mechanical loading only but further work has been done to cover thermal loading too. Extensive experimental work has also been addressing disc cooling characteristics which proved to be superior to the standard disc, with considerable improvements at all temperatures, speeds and flow conditions. At this stage, all evidence suggest that the design proposed is a valid, feasible solution being still relatively low cost as it can be manufactured as a single piece casting and machined in a usual way.

At the moment, the solution created is applicable to a light vehicle only (e.g. Lotus Elise) as heavier vehicle with 'deeper' top hat disc shapes typically create unacceptably high stresses in a fingered shaped hub. No doubt that other, more complex but well established manufacturing methods can be exploited, for instance Spheroidal Graphite (SG) cast iron fingered hub and Grey Iron (GI) disc ring. Fingered disc offers substantial possibilities in influencing NVH characteristics, as the change of disc natural frequencies in a fingered hub is much more effective than for a solid hub. Thermal stresses will be also necessary to be addressed and this is where multi objective optimization can be very useful. Obviously, further work is also needed in productionising the design, from producing the casting to performance and endurance testing on rigs, dynamometers, and finally vehicles. 


\section{Funding}

The generation of the initial fingered disc concept was partially supported by Eurac (Pool) Ltd Company as a part of a different project and the authors are most grateful for this provision.

\section{Acknowledgement}

Authors' particular thanks go to Dr David Eggleston and Mr Richard Sims from Eurac (Pool) Ltd for their input and support. With sadness and greatest respect the authors devote this article in memory of Dr Eggleston. The authors are most appreciative for the help received from Cranfield University colleagues: Dr Ricardo Correia with strain measurements, Dr Peter Sherar and Mr Philp Feig (a visiting student from TU Munich) with CAD modelling.

\section{Disclosure Statement}

No potential conflict of interest was reported by the authors.

\section{References}

Bakhtiary, N., Allinger, P., Friedrich, M., Mulfinger, F., Sauter, J., Müller O. and Puchinger, M., 1996. "A new approach for sizing, shape and topology optimization”, SAE Paper 960814.

Barton, D.C., 2018, “Disc Material Modelling”, in Course Notes, Disc Brake Design and Analysis Short Course, 13-15 March 2018, Cranfield University, UK.

Belhocine, A. and Omar W. Z. W., 2017. "Three-dimensional finite element modeling and analysis of the mechanical behavior of dry contact slipping between the disc and the brake pads" The International Journal of Advanced Manufacturing Technology, 88(1), 2017, pp. 1035-1051. 
Bendsøe, M. P. and Kikuchi, N., 1988. "Generating optimal topologies in structural design using a homogenization method." Computer methods in applied mechanics and engineering, 7(2), pp. 197-224.

Chiandussi, G., Gaviglio, I. and Ibba, A., 2004. "Topology optimization of an automotive component without final volume constraint specification." Advances in Engineering Software, 35(10), pp. 609-617.

Cho, H. J. and Cho, C. D., 2008. "A study of thermal and mechanical behaviour for the optimal design of automotive disc brakes." Proceedings of the Institution of Mechanical Engineers, Part D: Journal of Automobile Engineering, 222(6), pp. 895-915.

Deng, M. and Lan, J., 2016. “The Topology Optimization Analysis on Rope-Wheel Glass Lifter.” SAE Paper 2016-01-1384.

Dufrenoy, P. and Brunel, J.F., 2008. "Thermal localisation in friction brakes." SAE Paper 2008-01-2568.

Edara, R., 2006. "Heavy Vehicle Disc Brake Components Design Using CAE Tools." SAE Paper 2006-01-3559.

Goto, Y., Saomoto, H., Sugiura, N., Matsushima, T., Ito, S. and Fukui, A. 2010. "Structural design technology for brake squeal reduction using sensitivity analysis." SAE Paper 2010-01-1691.

Grieve, D. G., Barton, D. C., Crolla, D. A. and Buckingham, J. T., 1998. "Design of a lightweight automotive brake disc using finite element and Taguchi techniques." Proceedings of the Institution of Mechanical Engineers, Part D: Journal of Automobile Engineering, 212(4), pp. 245-254. 
Inoue, H., Hashimoto, K. and Kumemura, Y., 2015. “Study of Development Technology of Brake Caliper Which Balances Preventing Squeal with Weight Reduction.” SAE Paper 2015-01-2688.

Kumagai, M., Otomori, M., Ide, T., Yamada, T., Izui, K. and Nishiwaki, S., 2016. "Design Study of Lightweight Automatic Transmission Parts for Vehicles Using Level Set-Based Topology Optimization.” SAE Paper 2016-01-1386.

Laxman, S., Iyengar, R. M., Morgans, S. and Koganti, R., 2009. "Harnessing Structural Optimization Techniques for Developing Efficient Light-Weight Vehicles.” SAE Paper 2009-01-1234.

Mlejnek, H. P. and Schirrmacher, R., 1993. “An engineer's approach to optimal material distribution and shape finding." Computer methods in applied mechanics and engineering, 106(1-2), pp. 1-26.

Ogata, Y. S. S. and Hiraoka, M., 2005. "Development of topology optimization method for reduction of transmission housing weight." SAE Paper 2005-01-1699.

SAF Holland. http://www.safholland.com/, Accessed June 17, 2018.

Sergent, N., Tirovic, M. and Voveris, J., 2014. "Design optimization of an opposed piston brake caliper.” Engineering Optimization. 46(11), pp. 1520-1537.

Shin, J. K., Lee, K. H., Song, S. I. and Park, G. J., 2002. “Automotive door design with the ULSAB concept using structural optimization." Structural and Multidisciplinary Optimization. 23(4), pp. 320-327.

Strömberg, N., 2010. “An efficient trade-off approach for topology optimization with manufacturing constraints." In: Proceedings of the ASME International Design Engineering Technical Conference, Volume 1, Montreal, Quebec, Canada, August 15-18, 2010. pp. 1171-1179. 
Tang, J., Bryant, D. and Qi, H., 2018. "Experimental Investigation of the Dynamic Thermal Deformation and Judder of a Ventilated Disc Brake." Paper EB2018FBR-002, In Proceedings EuroBrake Conference, 22-24 May 2018, The Hague, Netherlands.

Tirovic, M. and Sarwar, G. A., 2004. "Design synthesis of non-symmetrically loaded high-performance disc brakes: Part 3: Verification and optimization.” Proceedings of the Institution of Mechanical Engineers, Part F: Journal of Rail and Rapid Transit, 218(2), pp. 105-115.

Topouris, S., 2017. "Design and Optimisation of a High Performance Lightweight Monoblock Cast Iron Brake Disc.” PhD Thesis, Cranfield University.

Vadiraj, A. and Tiwari, S., 2013. "Investigation on microstructure, mechanical and wear properties of alloyed gray cast iron for brake applications." SAE Paper 2013-012881.

Wang, G., Guo, X. and Zhou, Q., 2014. "Strength Analysis and Structural Optimization of Lever of Air Disc Brake.” SAE Paper 2014-01-2507.

Wang, L., Basu, P. K. and Leiva, J. P., 2004. “Automobile body reinforcement by finite element optimization.” Finite Elements in Analysis and Design, 40(8), pp. 879-893.

Xie, Y. M. and Steven, G. P., 1993. “A simple evolutionary procedure for structural optimization." Computers and structures, 49(5), pp. 885-896. 
2018-11-23

\section{Design synthesis and structural optimisation of a lightweight, monobloc cast iron brake disc with fingered hub}

Topouris, Stergios

Taylor and Francis

Topouris S, Tirovic M. Design synthesis and structural optimisation of a lightweight, monobloc cast iron brake disc with fingered hub. Engineering Optimization, Volume 51, Issue 10, 2019 , pp. 1710-1726

https://doi.org/10.1080/0305215X.2018.1542692

Downloaded from Cranfield Library Services E-Repository 